\title{
Hippocampal Volume Predicts Fluid Intelligence in Musically Trained People
}

\author{
Mathias S. Oechslin, 1,2,3* Céline Descloux, ${ }^{4}$ Alexandre Croquelois, ${ }^{4}$ \\ Julien Chanal, ${ }^{2}$ Dimitri Van De Ville, ${ }^{1,5,6}$ François Lazeyras, ${ }^{5}$ and \\ Clara E. James ${ }^{1,2,7}$
}

\begin{abstract}
Recently, age-related hippocampal (HP) volume loss could be associated with a decrease in general fluid intelligence (gF). In the present study we investigated whether and how extensive musical training modulates human HP volume and gF performance. Previously, some studies demonstrated positive effects of musical training on higher cognitive functions such as learning and memory, associated with neural adaptations beyond the auditory domain. In order to detect possible associations between musical training and $\mathrm{gF}$, we bilaterally segmented the HP formation and assessed the individual gF performance of people with different levels of musical expertise. Multiple regression analyses revealed that HP volume predicts $\mathrm{gF}$ in musicians but not in nonmusicians; in particular, bilaterally enhanced HP volume is associated with increased gF exclusively in musically trained people (amateurs and experts). This result suggests that musical training facilitates the recruitment of cognitive resources, which are essential for $\mathrm{gF}$ and linked to HP functioning. Musical training, even at a moderate level of intensity, can thus be considered as a potential strategy to decelerate age-related effects of cognitive decline. $\odot 2013$ Wiley Periodicals, Inc.
\end{abstract}

KEY WORDS: expertise; musicians; hippocampus; cognition; fluid intelligence; brain plasticity

\footnotetext{
${ }^{1}$ Geneva Neuroscience Center, University of Geneva, CH-1211 Geneva 4, Switzerland; ${ }^{2}$ Faculty of Psychology and Educational Sciences, University of Geneva, CH-1211 Geneva 4, Switzerland; ${ }^{3}$ International Normal Aging and Plasticity Center (INAPIC), University of Zurich, $\mathrm{CH}-8006$, Zurich, Switzerland; ${ }^{4}$ Department of Cell Biology and Morphology, University of Lausanne, CH-1015 Lausanne, Switzerland; ${ }^{5}$ Department of Radiology and Medical Informatics, Hôpitaux Universitaires de Genève, $\mathrm{CH}-1211$ Geneva 4, Switzerland; ${ }^{6}$ Institute of Bioengineering, École Polytechnique Fédérale de Lausanne, $\mathrm{CH}-1015$ Lausanne, Switzerland; ${ }^{7}$ School of Health Geneva, University of Applied Sciences Western Switzerland, CH-1206 Geneva, Switzerland Grant sponsor: Swiss National Science Foundation (part of a multibrain imaging project entitled Behavioral, neuro-functional, and neuroanatomical correlates of experience dependent music perception); Grant number: 100014-125050.

*Correspondence to: Mathias S. Oechslin, International Normal Aging and Plasticity Imaging Center (INAPIC), University of Zurich, Binzmühlestrasse 14/25, 8050 Zurich, Switzerland.

E-mail: mathias.oechslin@uzh.ch

Accepted for publication 12 March 2013

DOI 10.1002/hipo.22120

Published online 29 April 2013 in Wiley Online Library

(wileyonlinelibrary.com).
}

\section{INTRODUCTION}

The hippocampal (HP) formation is a highly plastic brain structure that generates neurons over the whole lifespan (Lledo et al., 2006). Investigations on $\mathrm{HP}$ function in healthy human adults could demonstrate that age-related HP volume loss predicts decrease in general fluid intelligence (gF) performance (Reuben et al., 2011). Therefore, it is of pertinent interest to ascertain possible interventions that could countervail HP volume loss and thus decelerate this effect of cognitive decline. Different positive factors, such as cognitive stimulation, meditation and physical exercises may modify HP structure and volume (review by Fotuhi et al., 2012). Musical activities constitute another promising influential factor due to the highly complex multimodal features of musical performance.

Extensive musical practice promotes functional and structural brain plasticity in auditory areas (auditory cortex: Schneider et al., 2002; Hyde et al., 2009; Meyer et al., 2012b; Oechslin et al., 2010b), auditory pathway microstructure (arcute fasciculus: Bengtsson et al., 2005; Oechslin et al., 2010a; Halwani et al., 2011), the motor system (somatosensory cortex: Elbert et al., 1995; corpus callosum: Schmithorst and Wilke, 2002; primary motor cortex: Hyde et al., 2009; corticospinal tract: Imfeld et al., 2009) and in areas involved in multisensory integration (Lee and Noppeney, 2011; Luo et al., 2012; James et al., in press). Previous reviews outlined the full panoply of training induced cortical adaptations; highlighting the role of the musical brain as one of the most prominent models in neuroscience to study brain plasticity (Schellenberg, 2001; Münte et al., 2002; Jäncke, 2009; Trainor et al., 2009; Kraus and Chandrasekaran, 2010; Wan and Schlaug, 2010; Besson et al., 2011; Pantev and Herholz, 2011; Penhune, 2011; Herholz and Zatorre, 2012; Meyer et al., 2012a; Schulze and Koelsch, 2012).

With respect to auditory cognition, it has been demonstrated that musical training changes the 
TABLE 1

Participant Information

\begin{tabular}{lccc}
\hline Groups & Age & Sex (f/m) & Start of musical training (age) \\
\hline E & $24.5( \pm 4.5)$ & $10 / 10$ & $6.2( \pm 1.9)$ \\
A & $22.2( \pm 3.1)$ & $10 / 10$ & $7( \pm 1.4)$ \\
N & $24.3( \pm 4.4)$ & $10 / 10$ & - \\
\hline
\end{tabular}

Mean values $( \pm S D)$; groups are matched by gender, age $\left(F_{2,56}=2.013\right.$, $P=0.143)$ and start of musical training $\left(F_{1,39}=2.224, P=0.144\right)$. Age of beginning was not significantly different between the two musician groups $\left(t_{38}=1.5, P=0.19\right)$.

memory structure of tonal representations (Oechslin et al., 2012) and furthermore, enhances tonal working memory (WM) (Parbery-Clark et al., 2011; Schulze et al., 2011) and attention (Strait and Kraus, 2011). Additionally, a recent study demonstrated enhanced visual WM capacities in professional musicians, and moreover, that individual training intensity predicted WM performance (Oechslin et al., in press). Far transfer effects (Barnett and Ceci, 2002) beyond the auditory domain have been infrequently reported in the literature. For instance, orchestral musicians showed enhanced visuospatial discrimination performance compared to nonmusicians (Sluming et al., 2007). With respect to the relationship between $\mathrm{gF}$ and musical training, Lynn et al. (1989) unveiled a positive correlation between the performance in several analytical musical tasks (chord analysis, pitch change perception and pitch memory) and matrix reasoning in school children. In a longitudinal approach Schellenberg (2004) demonstrated that musical training yields an increase in intelligence (WISC-III; Wechsler, 1991) compared to drama exercises. Forgeard et al. (2008) found that duration of musical training in children is positively correlated with vocabulary (subtest of WISC-III; Wechsler, 1991) and nonverbal logical reasoning (Raven's progressive matrices; Raven, 1995). Such beneficial effects of musical practice could be due to a relation between intelligence and executive control (Jaeggi et al., 2008). This hypothesis is supported by a recent study demonstrating improved executive functions as a result of short-term 20-day musical training (Moreno et al., 2012). In sum, transfer effects induced by musical training most likely occur if processing networks overlap anatomically, either on the level of sensory decoding (Patel, 2011), or, as presumed by the present investigation, on the level of higher cognitive functions.

Above introduced findings imply that deliberate musical training yields beneficial adaptations in brain structures related to learning and memory. The following additional reports back up this assumption related to HP adaptive plasticity. Musical expertise yielded enhanced HP responsiveness following unexpected musical closures by means of event-related potential source imaging (James et al., 2008). A longitudinal study revealed that after $1 \mathrm{yr}$ of intensive aural training, HP reactivity was enhanced in musical students during temporal novelty processing (Herdener et al., 2010). Furthermore, increased left HP gray matter density was found in musicians compared to nonmusicians (Groussard et al., 2010). The HP formation can thus be considered as susceptible to musical training-induced neuroplasticity, both on functional and structural bases.

In this context, we hypothesized that musical training modulates the relationship between HP volume and gF. To test this hypothesis we carried out structural brain imaging and subsequent manual HP segmentation in subjects with different levels of musical expertise and collected measures of $\mathrm{gF}$ performance. We used multiple regression analyses to examine the relationship between HP volume and $\mathrm{gF}$ performance and its modulations by musical training.

\section{MATERIALS AND METHODS}

According to strict inclusion and exclusion criteria, we recruited three groups ( $n=20$ each) of right-handed (Oldfield, 1971), normal hearing subjects of either sex, representing three distinct levels of musical expertise. Groups were matched for age and sex and consisted of nonmusicians $(\mathrm{N})$, amateur (A) and expert musicians (E). All A and E practiced the piano and started training at age 10 at the latest. Age at training onset was not significantly different between $\mathrm{A}$ and $\mathrm{E}$ (Table 1).

E were essentially advanced conservatory students but also established artists or teachers, who received their training at the Conservatoires of Geneva, Lausanne, Paris and Zurich. The criterion for being part of group A was defined as being still musically active at the moment of participating in this study, however, musical practice should have never exceeded $10 \mathrm{~h}$ per week (Table 2).

The concept of $\mathrm{gF}$ represents the ability to solve novel problems independently of prior knowledge (Cattell, 1971). Here we assessed the participants' $\mathrm{gF}$ performance by means of logical (inductive) reasoning in the visual modality by applying the standard measure of Raven's Advanced Progressive Matrices (Raven, 1995) in a time limited version (15 min). Test items

TABLE 2.

Musical Training Intensity

Training intensity

\begin{tabular}{lrrr}
\hline Age period & A (h/week) & E (h/week) & $t$-Values \\
\hline $6-8$ & $3.0( \pm 1.9)$ & $3.1( \pm 1.7)$ & 1.1 \\
$8-10$ & $3.5( \pm 0.5)$ & $4.2( \pm 0.5)$ & 1.1 \\
$10-12$ & $4( \pm 2.3)$ & $6.5( \pm 4.3)$ & $2.7^{*}$ \\
$12-14$ & $4.7( \pm 2.6)$ & $9( \pm 5.3)$ & $3.3^{* *}$ \\
$14-16$ & $5.3( \pm 3.2)$ & $14.8( \pm 7.7)$ & $5.1^{* * *}$ \\
$16-18$ & $4.7( \pm 2.2)$ & $19.9( \pm 9.3)$ & $7.1^{* * *}$ \\
$18-25$ & $4.4( \pm 2.9)$ & $30.7( \pm 8.5)$ & $12.4^{* * *}$ \\
\hline
\end{tabular}

Training intensities of the two groups of musicians (A/E) are reported in mean $( \pm \mathrm{SD})$ number of hours/week $(\mathrm{h} / \mathrm{w})$ within certain periods of life, and differences are tested by $t$-tests for independent samples [two-tailed, asterisks indicate level of significance: $P^{(*)}<0.05, P\left({ }^{* *}\right)<0.01, P\left({ }^{* *}\right)<0.001$ ] (for more details, see Oechslin et al., in press). 
A.
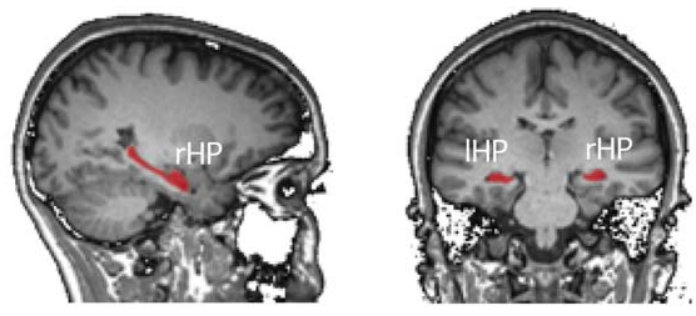

B.

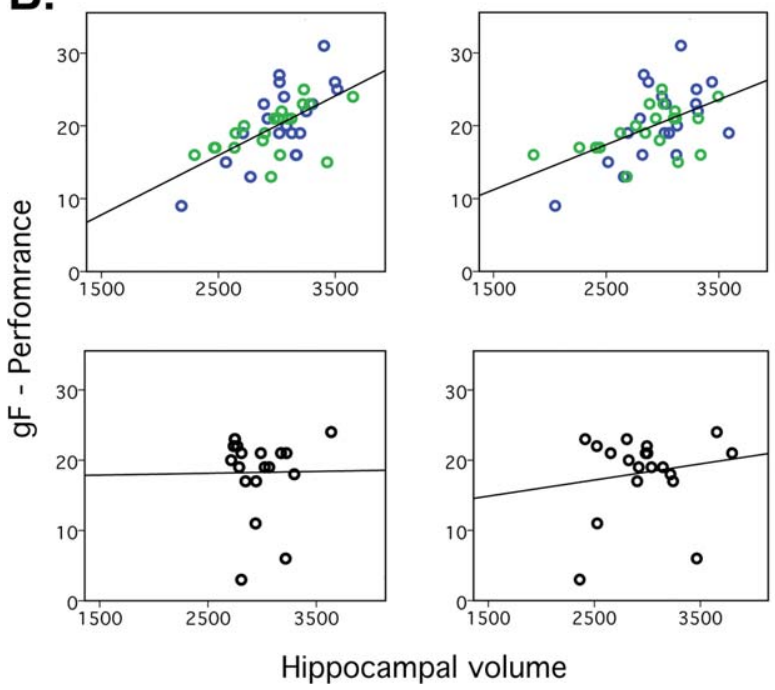

FIGURE 1. A. Segmentations of left and right hippocampus (lHP, rHP) of a single subject brain are highlighted in red. B. The individual hippocampal volume (number of voxels) is plotted against general fluid intelligence (gF) performance (absolute scores); linear regression lines are fitted. Left panels show 1HP, right panels rHP. The upper panel shows musicians [amateurs (blue) and professionals (green)]. Non-musicians (black) are displayed in the lower panel.

require the examinee to infer a rule relating to a collection of elements, with which the corresponding element, among several others, related to the correct rule shall be verified (Alderton and Larson, 1990). A single test item is characterized by a set of eight black-and-white elements, arranged in a $3 \times 3$ matrix. The missing ninth element completing the pattern has to be selected. Raven's test therefore probes for nonverbal intelligence in a multiple-choice manner. Subjects performed the original paper-pencil version of the Raven's test. Every test item was presented on a single page (36 items in total). Subjects were instructed to proceed in the predefined order without skipping single test items, since the preceding ones served as learning experience for later ones which became increasingly difficult (Spreen and Strauss, 1991).

In a previous study, we asked subjects to perform a visual three-back letter task (Ludwig et al., 2008), since underlying working memory (WM) mechanisms have been suggested to be closely related to $\mathrm{gF}$ assessed by matrix reasoning (Jaeggi et al., 2008, 2011; Jausovec and Jausovec, 2012). We administered this $\mathrm{n}$-back test to verify similar correlational effects and possible differences between musicians and non-musicians. For further details about the experimental set-up of this n-back paradigm, performed by the same participant groups as in the current study, we refer to the original communication (Oechslin et al., in press).

For each participant we recorded a T1-weighted rapid gradient-echo structural image (3-T scanner, Siemens TRIO, Erlangen Germany: $\mathrm{TE}=2.27 \mathrm{~ms}, \mathrm{TR}=1900 \mathrm{~ms}$, flip angle $=9$ deg., $\mathrm{FOV}=256 \times 256 \mathrm{~mm}^{2}$, slice thickness $=1$ $\mathrm{mm}$, inversion time $(\mathrm{TI})=900 \mathrm{~ms}$, voxel size $\left.=1 \mathrm{~mm}^{3}\right)$. Left (lHP) and right (rHP) HP formations were manually segmented for all subjects (example in Fig. 1A), resulting in volumes expressed in total number of voxels. Performing manual segmentation of the hippocampal structure represents the gold standard for most accurate volumetric measurement. A physician trained in neurology performed the segmentations after receiving intensive coaching for this procedure by a highly experienced neurologist. The investigator, blinded for group belonging and subjects' identity, performed segmentations both in the coronal and the sagittal plans to improve accuracy (using the software MRIcroN [http://www.mccauslandcenter.sc.edu/mricro/]). For the regression analyses we calculated the mean number of voxels taking into account both evaluations. The segmentation included hippocampus proper, dentate gyrus and subiculum and was performed in rostral to caudal direction. To clearly dissociate between hippocampus and amygdala we used the alveus (Hasboun et al., 1996; Tae et al., 2008), and the uncal recess of the inferior horn of the lateral ventricle as anterior landmarks (Watson et al., 1992; Pruessner et al., 2000). The hippocampal (choroid) fissure was used to determine the border with the entorhinal cortex along the coronal slices (Insausti et al., 1998). We delineated the tail completely, with the aid of the sagittal plane which makes the HP tail surround by white matter more apparent (McHugh et al., 2007); meaning inferior medially to the trigone of the lateral ventricle (Pruessner et al., 2000). One N subject was excluded from all analyses, since structural data acquisition was corrupted.

In order to analyze (i) to what extent we can predict $\mathrm{gF}$ performance by HP volume, and (ii) whether this prediction is modulated by the factor of musical training, we performed robust multiple regression analyses with $\mathrm{HH}$ and $\mathrm{rHP}$ volume as predictors for $\mathrm{gF}$.

\section{RESULTS}

In the robust multiple regression analyses amateurs (A) and expert musicians (E) were pooled into one group of "musicians" ( $\mathrm{M}, n=40)$, because correlations between $\mathrm{gF}$ and $1 \mathrm{HP} / \mathrm{rHP}$ volume did not significantly differ between both groups [unveiled by Fisher's $\mathrm{r}$ to $\mathrm{z}$ transformations testing the following correlations between $\mathrm{A}$ and $\mathrm{E}: \mathrm{gF}$ vs. $1 \mathrm{HP}$ : A $(r=0.700, P=0.005), \mathrm{E}(r=0.521, P=0.019)$; $\mathrm{gF}$ vs. $\mathrm{rHP}$ : A $(r=0.590, P=0.006), \mathrm{E}(r=0.479, P=0.033)$. Fisher's $\mathrm{r}$ 
to $\mathrm{z}$ transformation A vs. E: $\mathrm{LH}: \mathrm{z}=0.158, P=0.437$; $\mathrm{RH}$ : $\mathrm{z}=-0.295, P=0.382]$. Levene's test for equality of variances revealed no significant differences between $\mathrm{N}$ and $\mathrm{M}$ in $\mathrm{gF}$ and $\mathrm{HP}$ volumes $\left(\mathrm{gF}: F_{1,57}=0.360, \quad P=0.545 ; \quad \mathrm{HP}\right.$ : $F_{1,57}=1.077, P=0.304$; rHP: $\left.F_{1,57}=0.027, P=0.870\right)$. Preliminary analyses revealed that neither mean $\mathrm{gF}$ performance, nor $1 \mathrm{HP}$ and $\mathrm{rHP}$ volume significantly differed between $\mathrm{M}$ and $\mathrm{N} \quad\left(\mathrm{gF}: \quad F_{1,58}=0.723, \quad P=0.195 ; \quad \mathrm{HP}: \quad F_{1,58}=0.104\right.$, $P=0.748$; rHP: $F_{1.58}=0.199, P=0.658$ ).

Finally, we tested the predictability of $\mathrm{gF}$ by $\mathrm{HP}$ volume. The factor Expertise was represented by two levels of musical expertise in the regression models (,$n=19 ; \mathrm{M}, n=40$ ). Scatter plots and fitted linear regressions are delineated in Figure 1B. Significant interactions with Expertise in the left $[t=2.221, P=0.030 ; \mathrm{N}$ (beta $=0.03), \mathrm{M}($ beta $=0.46)]$ and the right hemisphere $[t=2.003, P=0.050 ; \mathrm{N}$ (beta $=0.01$ ), $\mathrm{M}$ (beta $=0.38)]$ revealed that bilateral HP volumes predict $\mathrm{gF}$ performance exclusively in musically trained people.

E subjects $($ mean $=84.4[\mathrm{SD}=7.1])$ exhibited significantly enhanced WM $\left(t_{38}=2.6, P=0.015\right)$ compared to $\mathrm{N}$ subjects $($ mean $=72.1 \quad[\mathrm{SD}=19.7])$, as assessed by the visual threeback letter task (max. score $=108)$; A subjects $($ mean $=75.8$ $[S D=19])$ performed on an intermediate level (previously reported by Oechslin et al., in press).

Supplementary analyses in the present context yielded a positive correlation between $\mathrm{gF}$ and $\mathrm{WM}$ in $\mathrm{M}[r=0.473$, $P=0.001]$ but not in $\mathrm{N}(r=0.225, P=0.177)$. One subject of group A has been excluded from this analysis due to low performance (score: 14 out of 108), probably induced by noncomprehension of the task instructions. Additional independent robust multiple regression analyses (including all subjects) revealed that the relationship between $\mathrm{gF}$ and $\mathrm{WM}$ interacts significantly with the factor Expertise $(\mathrm{N}, \mathrm{M})$, controlled for left $(t=6.409, P<0.001)$ and right HP volume $(t=3.295$, $P=0.002)$. No significant direct relationship was found between WM and HP volume.

\section{DISCUSSION}

For a deeper understanding of this finding and its underlying rationales, we would like to put forward two lines of explanation. First, previous investigations demonstrated that $\mathrm{gF}$ performance, especially when evaluated by matrix reasoning, correlated with WM capacity (as tested by means of a n-back task; (Jaeggi et al., 2010)). Moreover, gF performance even improved as a function of WM training intensity (Jaeggi et al., 2008). An overlap of cognitive processes involved in WM and $\mathrm{gF}$ may explain this transfer effect. For instance, attentional control plays a similar role both in WM and gF, namely to maintain bindings of different spatial and temporal elements in memory (review by Halford et al., 2007). Thus, gF performance may be mediated by shared cognitive functions also involved in WM performance and learning (Jaeggi et al., 2010).

Second, in a previous study including the same participants (Oechslin et al., in press), we hypothesized that musical training itself yields enhanced working memory capacities that apply not only to the auditory (Parbery-Clark et al., 2011; Schulze et al., 2011) but as well to the visual domain. In this previous work, we found (i) that musicians show enhanced visual WM capacities compared to non-musicians, and (ii) that individual performance could be predicted by training intensity (hours/week). This is in line with the assumption that complex musical behavior exceeds auditory perception, strengthening also audiovisual binding, multisensory and motor integration (Hodges et al., 2005; Lahav et al., 2007) as well as attention (Strait and Kraus, 2011), probably partially as a consequence of on-stage performance.

These two lines of explanation indicate an indirect relationship between musical training and gF. Given that instrumental practice represents an implicit way to hone WM capacity, a transfer effect to $\mathrm{gF}$, mediated by shared attentional control mechanisms, may take place as described above. Supplementary analyses confirmed this relationship by revealing a significant correlation between visual WM and $\mathrm{gF}$ in musicians but not in non-musicians. Accordingly, we assume that intensive musical practice entails indirect training of WM that benefits $\mathrm{gF}$ performance.

On the other hand, the present data revealed no statistically significant relationship between WM and HC volume in none of our subject groups. Diverging findings in literature either evidenced such a relationship (Olson et al., 2006; Ezzyat and Olson, 2008) or not (Cowey and Green, 1996; Baddeley et al., 2010; Jeneson et al., 2010). Finally, the recent work by Li et al. (2010, in press), who assessed WM as well by n-back tasks, strongly suggests, that this dependency is modulated by a specific dopamine regulating gene polymorphism (NTSR1). The interaction between gene factors and certain training strategies that enhance WM or decelerate the decay of WM capacities over the lifespan needs to be addressed in future studies.

So far a number of studies reported different conditions under which HP growth has been observed (review by Fotuhi et al., 2012): cognitive stimulation (Maguire et al., 2000; Draganski et al., 2006; Fortin et al., 2008), physical exercises (Erickson et al., 2010; Pajonk et al., 2010) and meditation (Luders et al., 2009; Holzel et al., 2011) yield increased HP neurogenesis. Recent research support the assumption that the present finding, namely that piano practice could promote HP growth, is rather related to cognitive-perceptual than motor aspects: Using an implicit learning task (finger tapping sequence), Rose et al. (2011) demonstrated bilateral learningrelated increase of HP activations as a consequence of perceptual sequence learning but not motor sequence learning. In case of musicians, this dissociation therefore indicates that aspects of auditory learning and related cognitive mechanisms are crucial for HP plasticity. The possible nature of these mechanisms has been further enlightened by a very recent study revealing that HP grey matter density is positively 
correlated with years of piano tuning (Teki et al., 2012). In contrast to pianists, piano tuners do not especially train their hand-motor skills. Nevertheless, both populations share honed auditory competence due to intensive auditory training, consolidated as a cognitive representation of acoustic and harmonic features. As previously evidenced, this harmonic system is topographically organized and quantifiable by spatial characteristics (Janata et al., 2002; Toiviainen and Krumhansl, 2003). The resulting cognitive tonal map is relatively stable across skilled listeners and, moreover, can be acquired even by implicit perceptual learning (Oechslin et al., 2012). We thus argue, that active listening and playing music is constantly accompanied by tonal referencing or navigating through a cognitive representation, a mental soundscape defined by the stored harmonic system. As already pointed out by Teki et al. (2012), conceptually, mental navigation in tonal space is very similar to spatial navigation, whereas the latter as well has been associated with expertise-dependent HP plasticity (Woollett and Maguire, 2011). We therefore conclude that deliberate musical practice stimulates similar mechanisms yielding increased HP neurogenesis. Additionally, the underlying cellular mechanisms of HP growth might be supported by positive experiences related to musical performance: Takahashi and colleagues (2009) demonstrated that enhanced HP neurogenesis is linked to reward. Therefore, the dopaminergic system could play a supportive role in HP growth associated with musical training, a relationship that might be based on pleasurable listening and performance experiences (Blood and Zatorre, 2001; Menon and Levitin, 2005) in combination with specific rewards linked to musical activities (Berridge and Robinson, 2003).

Although the macroscopic level of our analyses does not allow drawing any direct conclusions on the nature of the underlying microscopic mechanisms involved, HP volume increase is assumed to be a consequence of increased neurogenesis, basically as a result of promoting newborn cell survival in the subgranular zone of the HP dentate gyrus (reviews by Gage, 2000; Lledo et al., 2006).

The fact that $\mathrm{A}$ and $\mathrm{E}$ musicians expressed a similar relationship between $\mathrm{HC}$ volume and $\mathrm{gF}$ performance can be explained by their equal training intensity of $\mathrm{A}$ musicians in relation to E musicians (cf. Table 2): Between the age of 6 and $10 \mathrm{yr}$, training intensity between these two groups was equal in magnitude (cf. Table 1, James et al., in press). These retrospective data thus speak in favor that increased HC volume growth has been initiated most likely within this period. Previous investigations outlined that the brain in early childhood is most susceptible to experience driven plasticity (i.e., Schlaug et al., 1995; Imfeld et al., 2009; Pascual-Leone et al., 2012). Accordingly, a number of findings give rise to the assumption that the age of seven is critical with respect to the acquisition of advanced musical abilities and associated neural correlates (Penhune, 2011; Bailey and Penhune, 2012; Steele et al., 2013). Our data suggest that musical training before a certain critical age induces benefits for $\mathrm{gF}$ performance, analogous with language acquisition (Sakai, 2005) or development of absolute pitch (rare ability to identify a musical tone without any external reference (Russo et al., 2003; Deutsch et al., 2006)).

The observation that $\mathrm{HC}$ volume and $\mathrm{gF}$ do not simply increase with musical training (no mean group differences) but only in conjunction, implies an inhomogeneity in musicians with respect to the efficacy of deliberate practice: apparently, not everybody profits of musical training in the same way. Whether this is the consequence of different training strategies or predisposition cannot be disentangled by cross sectional investigations.

In sum, the present findings suggest that musical training, even at amateur level, can facilitate the recruitment of cognitive resources (working memory) that essentially contribute to $\mathrm{gF}$ and are linked to HP functioning. This discovery provides an additional corroboration of musicians' brain plasticity that even impacts on daily routines requiring conclusive thinking. The possible decelerating potential of musical training on agerelated cognitive decline, or its favorable effects during childhood and adolescence, needs further investigations within the context of lifespan development.

\section{Acknowledgments}

The authors thank Lars Rogenmoser for his valuable comments on an earlier version of the manuscript.

\section{REFERENCES}

Alderton DL, Larson GE. 1990. Dimensionality fo Raven's advanced progressive matrices items. Educ Psychol Meas 50:887-900.

Baddeley A, Allen R, Vargha-Khadem F. 2010. Is the hippocampus necessary for visual and verbal binding in working memory? Neuropsychologia 48:1089-1095.

Bailey J, Penhune VB. 2012. A sensitive period for musical training: Contributions of age of onset and cognitive abilities. Ann N Y Acad Sci 1252:163-170.

Barnett SM, Ceci SJ. 2002. When and where do we apply what we learn? A taxonomy for far transfer. Psychol Bull 128:612-637.

Bengtsson SL, Nagy Z, Skare S, Forsman L, Forssberg H, Ullen F. 2005. Extensive piano practicing has regionally specific effects on white matter development. Nat Neurosci 8:1148-1150.

Berridge KC, Robinson TE. 2003. Parsing reward. Trends Neurosci 26:507-513.

Besson M, Chobert J, Marie C. 2011. Transfer of training between music and speech: Common processing, attention, and memory. Front Psychol 2:94.

Blood AJ, Zatorre RJ. 2001. Intensely pleasurable responses to music correlate with activity in brain regions implicated in reward and emotion. Proc Natl Acad Sci USA 98:11818-11823.

Cattell RB. 1971. Abilities: Their Structure, Growth, and Action. New York: Houghton Mifflin.

Cowey CM, Green S. 1996. The hippocampus: A "working memory" structure? The effect of hippocampal sclerosis on working memory. Memory 4:19-30.

Deutsch D, Henthorn T, Marvin E, Xu H. 2006. Absolute pitch among American and Chinese conservatory students: Prevalence differences, and evidence for a speech-related critical period. J Acoust Soc Am 119:719-722. 
Draganski B, Gaser C, Kempermann G, Kuhn HG, Winkler J, Buchel C, May A. 2006. Temporal and spatial dynamics of brain structure changes during extensive learning. J Neurosci 26:6314-6317.

Elbert T, Pantev C, Wienbruch C, Rockstroh B, Taub E. 1995. Increased cortical representation of the fingers of the left hand in string players. Science 270:305-307.

Erickson KI, Voss MW, Prakash RS, Basak C, Szabo A, Chaddock L, Kim JS, Heo S, Alves H, White SM and others. 2010. Exercise training increases size of hippocampus and improves memory. Proc Natl Acad Sci USA 108:3017-3022.

Ezzyat Y, Olson IR. 2008. The medial temporal lobe and visual working memory: Comparisons across tasks, delays, and visual similarity. Cogn Affect Behav Neurosci 8:32-40.

Forgeard M, Winner E, Norton A, Schlaug G. 2008. Practicing a musical instrument in childhood is associated with enhanced verbal ability and nonverbal reasoning. PLoS One 3:e3566.

Fortin M, Voss P, Lord C, Lassonde M, Pruessner J, Saint-Amour D, Rainville C, Lepore F. 2008. Wayfinding in the blind: Larger hippocampal volume and supranormal spatial navigation. Brain 131(Pt 11):2995-3005.

Fotuhi M, Do D, Jack C. 2012. Modifiable factors that alter the size of the hippocampus with ageing. Nat Rev Neurol 8:189-202.

Gage FH. 2000. Mammalian neural stem cells. Science 287:14331438.

Groussard M, LaJoie R, Rauchs G, Landeau B, Chetelat G, Viader F, Desgranges B, Eustache F, Platel H. 2010. When music and longterm memory interact: Effects of musical expertise on functional and structural plasticity in the hippocampus. PLoS One 5.

Halford GS, Cowan N, Andrews G. 2007. Separating cognitive capacity from knowledge: A new hypothesis. Trends Cogn Sci 11:236-242.

Halwani GF, Loui P, Ruber T, Schlaug G. 2011. Effects of practice and experience on the arcuate fasciculus: Comparing singers, instrumentalists, and non-musicians. Front Psychol 2:156.

Hasboun D, Chantome M, Zouaoui A, Sahel M, Deladoeuille M, Sourour N, Duyme M, Baulac M, Marsault C, Dormont D. 1996. MR determination of hippocampal volume: Comparison of three methods. AJNR Am J Neuroradiol 17:1091-1098.

Herdener M, Esposito F, diSalle F, Boller C, Hilti CC, Habermeyer B, Scheffler K, Wetzel S, Seifritz E, Cattapan-Ludewig K. 2010. Musical training induces functional plasticity in human hippocampus. J Neurosci 30:1377-1384.

Herholz SC, Zatorre RJ. 2012. Musical training as a framework for brain plasticity: Behavior, function, and structure. Neuron 76:486502.

Hodges DA, Hairston WD, Burdette JH. 2005. Aspects of multisensory perception: The integration of visual and auditory information in musical experiences. Ann N Y Acad Sci 1060:175-185.

Holzel BK, Carmody J, Vangel M, Congleton C, Yerramsetti SM, Gard T, Lazar SW. 2011. Mindfulness practice leads to increases in regional brain gray matter density. Psychiatry Res 191:36-43.

Hyde KL, Lerch J, Norton A, Forgeard M, Winner E, Evans AC, Schlaug G. 2009. Musical training shapes structural brain development. J Neurosci 29:3019-3025.

Imfeld A, Oechslin MS, Meyer M, Loenneker T, Jancke L. 2009. White matter plasticity in the corticospinal tract of musicians: A diffusion tensor imaging study. Neuroimage 46:600-607.

Insausti R, Juottonen K, Soininen H, Insausti AM, Partanen K, Vainio P, Laakso MP, Pitkanen A. 1998. MR volumetric analysis of the human entorhinal, perirhinal, and temporopolar cortices. AJNR Am J Neuroradiol 19:659-671.

Jaeggi SM, Buschkuehl M, Jonides J, Perrig WJ. 2008. Improving fluid intelligence with training on working memory. Proc Natl Acad Sci USA 105:6829-6833.

Jaeggi SM, Buschkuehl M, Jonides J, Shah P. 2011. Short- and longterm benefits of cognitive training. Proc Natl Acad Sci USA 108:10081-10086.
Jaeggi SM, Studer-Luethi B, Buschkuehl M, Su Y-F, Jonides J, Perrig WJ. 2010. The relationship between n-back performance and matrix reasoning-Implications for training and transfer. Intelligence 28:625-635.

James CE, Britz J, Vuilleumier P, Hauert C-A, Michel CM. 2008. Early neuronal responses in right limbic structures mediate harmony incongruity processing in musical experts. Neuroimage 42:1597-1608.

James CE, Oechslin MS, Van DeVille D, Hauert C-A, Déscloux C, Lazeyras F. Musical training intensity yields opposite effects on grey matter density in cognitive versus sensorimotor networks. Brain Struct Funct (in press), doi:10.1007/s00429-013-0504-z.

Janata P, Birk JL, VanHorn JD, Leman M, Tillmann B, Bharucha JJ. 2002. The cortical topography of tonal structures underlying Western music. Science 298:2167-2170.

Jäncke L. 2009. The plastic human brain. Restor Neurol Neurosci 27:521-538.

Jausovec N, Jausovec K. 2012. Working memory training: Improving intelligence-Changing brain activity. Brain Cogn 79:96-106.

Jeneson A, Mauldin KN, Squire LR. 2010. Intact working memory for relational information after medial temporal lobe damage. J Neurosci 30:13624-13629.

Kraus N, Chandrasekaran B. 2010. Music training for the development of auditory skills. Nat Rev Neurosci 11:599-605.

Lahav A, Saltzman E, Schlaug G. 2007. Action representation of sound: Audiomotor recognition network while listening to newly acquired actions. J Neurosci 27:308-314.

Lee H, Noppeney U. 2011. Long-term music training tunes how the brain temporally binds signals from multiple senses. Proc Natl Acad Sci USA 108:E1441-E1450.

Li J, Chen C, He Q, Li H, Moyzis RK, Xue G, Dong Q. 2010. Neurotensin receptor 1 gene (NTSR1) polymorphism is associated with working memory. PLoS One 6:e17365.

Li J, Chen C, Lei X, Wang Y, He Q, Moyzis RK, Xue G, Zhu B, Cao Z, Dong Q. The NTSR1 gene modulates the association between hippocampal structure and working memory performance. Neuroimage (in press).

Lledo PM, Alonso M, Grubb MS. 2006. Adult neurogenesis and functional plasticity in neuronal circuits. Nat Rev Neurosci 7:179-193.

Luders E, Toga AW, Lepore N, Gaser C. 2009. The underlying anatomical correlates of long-term meditation: Larger hippocampal and frontal volumes of gray matter. Neuroimage 45:672-678.

Ludwig C, Chicherio C, Terraneo L, Slosman DO, Magistretti PJ, deRibaupierre A. 2008. Functional imaging studies of cognition using 99mTc-HMPAO SPECT: Empirical validation using the $\mathrm{n}$ back working memory paradigm. Eur J Nucl Med Mol Imaging 35:695-703.

Luo C, Guo ZW, Lai YX, Liao W, Liu Q, Kendrick KM, Yao DZ, Li H. 2012. Musical training induces functional plasticity in perceptual and motor networks: Insights from resting-state FMRI. PLoS One 7:e36568.

Lynn R, Wilson G, Gault A. 1989. Simple musical tests as measures of spearman's g. Person Individual Differ 10:25-28.

Maguire EA, Gadian DG, Johnsrude IS, Good CD, Ashburner J, Frackowiak RS, Frith CD. 2000. Navigation-related structural change in the hippocampi of taxi drivers. Proc Natl Acad Sci USA 97:4398-4403.

McHugh TL, Saykin AJ, Wishart HA, Flashman LA, Cleavinger HB, Rabin LA, Mamourian AC, Shen L. 2007. Hippocampal volume and shape analysis in an older adult population. Clin Neuropsychol 21:130-145.

Menon V, Levitin DJ. 2005. The rewards of music listening: Response and physiological connectivity of the mesolimbic system. Neuroimage 28:175-184.

Meyer M, Elmer S, Jancke L. 2012a. Musical expertise induces neuroplasticity of the planum temporale. Ann N Y Acad Sci 1252:116-123. 
Meyer M, Elmer S, Ringli M, Oechslin MS, Baumann S, Jäncke L. 2012b. Long-term exposure to music enhances the sensitivity of the auditory system in children. Eur J Neurosci 34:755-765.

Moreno S, Bialystok E, Barac R, Schellenberg EG, Cepeda NJ, Chau T. 2012. Short-term music training enhances verbal intelligence and executive function. Psychol Sci 22:1425-1433.

Münte TF, Altenmüller E, Jäncke L. 2002. The musician's brain as a model of neuroplasticity. Nat Rev Neurosci 3:473-478.

Oechslin MS, Imfeld A, Loenneker T, Meyer M, Jäncke L. 2010a. The plasticity of the superior longitudinal fasciculus as a function of musical expertise: A diffusion tensor imaging study. Front Hum Neurosci 3:76.

Oechslin MS, Läge D, Vitouch O. 2012. Training of tonal similarity ratings in non-musicians: A "rapid learning" approach. Front Psychol 3:142.

Oechslin MS, Meyer M, Jäncke L. 2010b. Absolute pitch-Functional evidence of speech-relevant auditory acuity. Cereb Cortex 20:447-455.

Oechslin MS, Van DeVille D, Lazeyras F, James JE. Degree of musical expertise modulates higher order brain functioning. Cerebal Cortex (in press), doi: 10.1093/cercor/bhs206.

Oldfield RC. 1971. The assessment and analysis of handedness: The Edinburgh inventory. Neuropsychologia 9:97-113.

Olson IR, Moore KS, Stark M, Chatterjee A. 2006. Visual working memory is impaired when the medial temporal lobe is damaged. J Cogn Neurosci 18:1087-1097.

Pajonk FG, Wobrock T, Gruber O, Scherk H, Berner D, Kaizl I, Kierer A, Muller S, Oest M, Meyer T and others. 2010. Hippocampal plasticity in response to exercise in schizophrenia. Arch Gen Psychiatry 67:133-143.

Pantev C, Herholz SC. 2011. Plasticity of the human auditory cortex related to musical training. Neurosci Biobehav Rev 35:2140-2154.

Parbery-Clark A, Strait DL, Anderson S, Hittner E, Kraus N. 2011. Musical experience and the aging auditory system: Implications for cognitive abilities and hearing speech in noise. PLoS One 6:e18082.

Pascual-Leone A, Freitas C, Oberman L, Horvath JC, Halko M, Eldaief M, Bashir S, Vernet M, Shafi M, Westover B and others. 2012. Characterizing brain cortical plasticity and network dynamics across the age-span in health and disease with TMS-EEG and TMS-fMRI. Brain Topogr 24:302-315.

Patel AD. 2011. Why would Musical Training Benefit the Neural Encoding of Speech? The OPERA Hypothesis. Front Psychol 2:142.

Penhune VB. 2011. Sensitive periods in human development: Evidence from musical training. Cortex 47:1126-1137.

Pruessner JC, Li LM, Serles W, Pruessner M, Collins DL, Kabani N, Lupien S, Evans AC. 2000. Volumetry of hippocampus and amygdala with high-resolution MRI and three-dimensional analysis software: Minimizing the discrepancies between laboratories. Cereb Cortex 10:433-442.

Raven JC. 1995. Advanced Progressive Matrices Sets I and II. Oxford: Oxford Psychologist Press Ltd.

Reuben A, Brickman AM, Muraskin J, Steffener J, Stern Y. 2011. Hippocampal atrophy relates to fluid intelligence decline in the elderly. J Int Neuropsychol Soc 17:56-61.

Rose M, Haider H, Salari N, Buchel C. 2011. Functional dissociation of hippocampal mechanism during implicit learning based on the domain of associations. J Neurosci 31:13739-13745.

Russo F, Windell D, Cuddy L. 2003. Learning the "Special Note": Evidence for a critical period for absolute pitch acquisition. Music Percept 21:119-127.
Sakai KL. 2005. Language acquisition and brain development. Science 310:815-819.

Schellenberg EG. 2001. Music and nonmusical abilities. Ann N Y Acad Sci 930:355-371.

Schellenberg EG. 2004. Music lessons enhance IQ. Psychol Sci 15:511-514.

Schlaug G, Jancke L, Huang Y, Staiger JF, Steinmetz H. 1995. Increased corpus callosum size in musicians. Neuropsychologia 33:1047-1055.

Schmithorst VJ, Wilke M. 2002. Differences in white matter architecture between musicians and non-musicians: a Diffusion tensor imaging study. Neurosci Lett 321:57-60.

Schneider P, Scherg M, Dosch HG, Specht HJ, Gutschalk A, Rupp A. 2002. Morphology of Heschl's gyrus reflects enhanced activation in the auditory cortex of musicians. Nat Neurosci 5:688-694.

Schulze K, Koelsch S. 2012. Working memory for speech and music. Ann N Y Acad Sci 1252:229-236.

Schulze K, Zysset S, Mueller K, Friederici AD, Koelsch S. 2011. Neuroarchitecture of verbal and tonal working memory in nonmusicians and musicians. Hum Brain Mapp 32:771-783.

Sluming V, Brooks J, Howard M, Downes JJ, Roberts N. 2007. Broca's area supports enhanced visuospatial cognition in orchestral musicians. J Neurosci 27:3799-3806.

Spreen O, Strauss E. 1991. A compendium of Neuropsychological Tests: Administration, Norms, and Commentary. New York: Oxford University Press.

Steele CJ, Bailey JA, Zatorre RJ, Penhune VB. 2013. Early musical training and white-matter plasticity in the corpus callosum: Evidence for a sensitive period. J Neurosci 33:1282-1290.

Strait DL, Kraus N. 2011. Can you hear me now? Musical training shapes functional brain networks for selective auditory attention and hearing speech in noise. Front Psychol 2:113.

Tae WS, Kim SS, Lee KU, Nam EC, Kim KW. 2008. Validation of hippocampal volumes measured using a manual method and two automated methods (FreeSurfer and IBASPM) in chronic major depressive disorder. Neuroradiology 50:569-581.

Takahashi T, Zhu Y, Hata T, Shimizu-Okabe C, Suzuki K, Nakahara D. 2009. Intracranial self-stimulation enhances neurogenesis in hippocampus of adult mice and rats. Neuroscience 158:402-411.

Teki S, Kumar S, vonKriegstein K, Stewart L, Lyness CR, Moore BC, Capleton B, Griffiths TD. 2012. Navigating the auditory scene: An expert role for the hippocampus. J Neurosci 32:12251-12257.

Toiviainen P, Krumhansl CL. 2003. Measuring and modeling realtime responses to music: The dynamics of tonality induction. Perception 32:741-766.

Trainor LJ, Shahin AJ, Roberts LE. 2009. Understanding the benefits of musical training: Effects on oscillatory brain activity. Ann N Y Acad Sci 1169:133-142.

Wan CY, Schlaug G. 2010. Music making as a tool for promoting brain plasticity across the life span. Neuroscientist 16:566-577.

Watson C, Andermann F, Gloor P, Jones-Gotman M, Peters T, Evans A, Olivier A, Melanson D, Leroux G. 1992. Anatomic basis of amygdaloid and hippocampal volume measurement by magnetic resonance imaging. Neurology 42:1743-1750.

Wechsler D. 1991. Wechsler Intelligence Scale for Children-Third Edition. San Antonio, TX: Psychological Corp.

Woollett K, Maguire EA. 2011. Acquiring "the Knowledge" of London's layout drives structural brain changes. Curr Biol 21:21092114. 